\title{
Reproductive Biology in Northern Prickly Ash
}

\author{
David A. Munter ${ }^{1}$, James J. Luby ${ }^{2}$, and Neil O. Anderson ${ }^{2,3}$ \\ Department of Horticultural Science, University of Minnesota, 305 Alderman Hall, 1970 Folwell \\ Avenue, Saint Paul, MN 55108
}

\begin{abstract}
AdDitional INDEX wORDs. autonomous apomixis, citrus, hermaphrodism, seedlessness, stenospermocarpy
Abstract. Zanthoxylum americanum is a common understory species in the northern forests of Minnesota and surrounding regions. It has potential economic importance for its citrus fragrance, pharmacological or insecticidal properties, and produces peppercorns similar to those of the related Zanthoxylum species. Zanthoxylum americanum is a dioecious species but has been reported to have aberrant flowers with autonomous apomixis instead of other potential reproductive barriers. The reproductive biology of Zanthoxylum americanum was investigated in two native Minnesota populations. Determinations of male fertility, whether autonomous apomixis was the predominant floral reproductive mechanism, the presence of seedless fruit (parthenocarpy/stenospermocarpy), and the occurrence of hermaphrodism were made over 2 years. Sex ratios (female:male plants) within each population differed. The mean pollen stainability was $95.8 \% \pm 0.3 \%$ (fresh) and $78.6 \% \pm 1.1 \%$ (stored 18 months). Parthenocarpy did not occur in either population. Autonomous apomixis was not the primary floral reproductive mechanism. Stenospermocarpy (seedlessness) occurred in $\mathbf{1 3 \%}$ of the female fruit clusters. Although commonly described as being dioecious, two additional reproductive strategies were identified: 1) plants with functional protandrous flowers with rudimentary pistils and 2) hermaphroditic flowers with fully functional pistils (protogynous) and anthers. As many as $10 \%$ to $30 \%$ of the male plants bore at least one fruit/plant each year. One clonal stand had both hermaphroditic and functionally staminate flowers on the same plant. Two evolutionary pathways to dioecy in $Z$. americanum are proposed.
\end{abstract}

Northern prickly ash or toothache tree, Z. americanum (Rutaceae), is a thorny constituent of the Minnesota forest understory landscape (Owenby and Morley, 1991; Porter, 1976). It resembles the ash tree (Fraxinus sp.) but is not related (Missouri Botanical Gardens, 2014). Zanthoxylum americanum is native to the northern portion of the United States as well as to parts of Canada, placing its most northerly range in the U.S. Department of Agriculture Zone 3 (U.S. Department of Agriculture, 2012a). Other species of Zanthoxylum grow in more southerly regions of the United States and other parts of the world such as Asia (Porter, 1976). Zanthoxylum americanum grows at the edges of forested areas as clonal stands (Reinartz and Popp, 1987) ranging from 1 to $8 \mathrm{~m}$ in height, producing clusters of small berry-like follicles or peppercorns $(0.5-0.6 \mathrm{~cm})$ adjacent to sharp thorns (U.S. Department of Agriculture, 2012a). The berrylike follicles have some of the characteristics of citrus (Citrus sp.) - strong citrus/lemon scent and an outer peel similar to citrus peels - but have missing horticulturally important traits such as large fruit size, multiple ovules, and juice vesicles. The fruit and bark produce a numbing sensation in the mouth and were purportedly used by Native Americans to treat toothaches (Erichsen-Brown and Brown, 1989). Other members of Zanthoxylum produce a similar numbing sensation, which is the basis of their use in Sichuan cooking (Damery, 2011; Katzer, n.d.).

Floral morphology in $Z$. americanum reportedly is structurally dioecious, with pistillate and staminate flowers on separate

\footnotetext{
Received for publication 13 Oct. 2017. Accepted for publication 29 Dec. 2017. This work was supported, in part, by funding from the Minnesota Agricultural Experiment Station. Special thanks to the Washington County Parks for allowing the study to take place within Cottage Grove Ravine Regional Park and St. Croix Bluffs Regional Park. Many thanks to David Biesboer for review of earlier manuscript drafts.

${ }^{1}$ Graduate Research Assistant.

${ }^{2}$ Professor.

${ }^{3}$ Corresponding author. E-mail: ander044@umn.edu.
}

plants, but reports of hermaphrodism (having flowers with functional stamens and pistils) also occur (Ainsworth, 2000; Felter and Lloyd, 1898). The inconspicuous flowers arise in clusters from axillary buds on old wood, with slender pubescent pedicels (Owenby and Morley, 1991). The small flowers lack a calyx and generally have five petals. The pistils usually number from three to five with slender styles; stamens usually number five per flower. Anthesis occurs in late April to May.

Little research has been published on $Z$. americanum in general and even less so on its sexual reproduction. Although there has been some research into its pharmacological properties (Bafi-Yeboa et al., 2005; Ju et al., 2001; Patiño et al., 2011), much of the remaining research focuses on $Z$. americanum from an ancillary perspective, i.e., its role as a host for the swallowtail butterfly [Papilio cresphontes (West and Hazel, 1996)], a potential pollinator or its function in the native ecosystem (Augspurger, 2009; Henderson et al., 1985).

The Rutaceae has a mixture of reproductive mechanisms (Bawa, 1980; Hartley and Mabberley, 2003). Sexual mechanisms include self-compatible hermaphrodites such as in citron 'Vozza Vozza' [Citrus medica (Distefano et al., 2012)], self-incompatible hermaphrodites $\{$ e.g., mandarin 'Clementine' [Citrus clementine or Citrus reticulata var. clementine (Distefano et al., 2009)]\}, and dioecious species such as some Zanthoxylum species (Freeman et al., 1997; Popp and Reinartz, 1988). A parallel asexual reproductive mechanism-apomixis (asexual reproduction through seeds) - arising from nucellar tissues, coupled with polyembryony - also exists in some of the citrus species such as sweet orange (Citrus sinensis) as well as the close citrus relative Poncirus trifoliata (Aleza et al., 2010; Cameron and Garber, 1968; Chen et al., 2008; Kepiro and Roose, 2007).

Apomixis (Nogler, 1984; Savidan, 1999) has also been reported in the genus Zanthoxylum (Desai, 1962; Naumova, 1992; Yinghong et al., 1987), although the type of apomixis occurring in the species varies. Desai (1962) found that four Zanthoxylum species (Z. americanum, Z. bungei, Z. simulans, 
and Z. planispinum) were autonomous apomicts, with no indication of fertilization. However, according to Naumova (1992), nucellar embryony was the only method of seed production in Zanthoxylum alatum, Z. americanum, Z. bungei, Z. planispinum, and $Z$. simulans. Naumova (1992) also stated that a few Zanthoxylum species had "exclusively" adventive embryony.

Because apomixis produces maternal clones, in the long term, apomixis in any dioecious species would have to be facultative; species-wide obligate apomixis would eventually remove all males from the species (Asker, 1979; Bicknell and Koltunow, 2004; Koltunow, 1993). This assumes that sexual expression in a species is completely under genetic control. It may be that sexual expression in a dioecious species such as $Z$. americanum is determined by a combination of genetics and environment (Mosseler and Zsuffa, 1989).

Dioecious plant species are theorized to develop via several pathways (Ainsworth, 2000; Darwin, 1877; Pannell, 2002; Ross, 1982; Webb, 1979). The particular pathway taken by a species can be partially inferred by examining its flower sexual typeshermaphrodite, pistillate, staminate, or distylous - and determining which flower types coexist on individual plants in the species populations being studied. According to Barrett (2002), the most common pathways (Fig. 1) are some variants of hermaphroditemonoecious-dioecious (Fig. 1D) or hermaphrodite-gynodioeciousdioecious (Fig. 1E). Additional pathways have also been described (Fig. 1) (Barrett, 2002; Bawa, 1980; Pannell, 2002; Ross, 1980, 1982; Webb, 1979).

Expression of dioecy may not have complete penetrance (termed subdioecious), with dioecious plants exhibiting signs that they have not yet completed their transition to dioecy, have reached some equilibrium state, or are evolving beyond a pure dioecious state (Darwin, 1877; Pannell, 2002; Ross, 1982; Webb, 1979). These subdioecious species often have individuals that
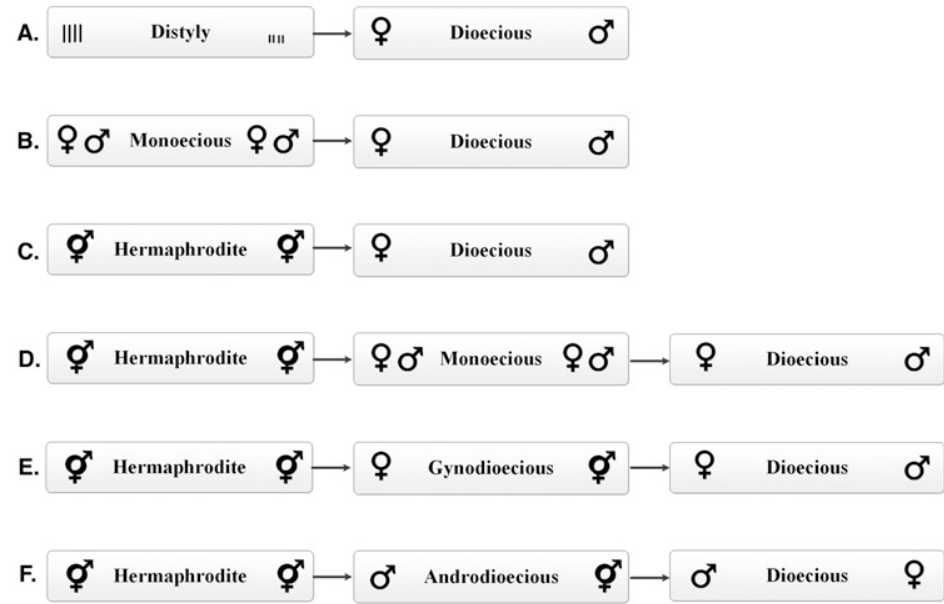

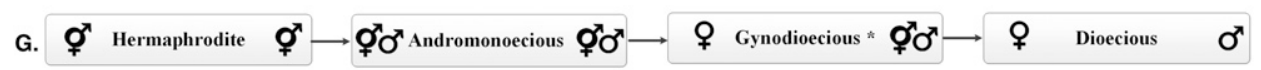

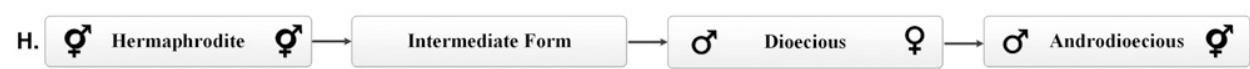

Fig. 1. Proposed paths to dioecy or subdioecy (Barrett, 2002; Bawa, 1980; Pannell, 2002; Ross, 1980, 1982; Webb, 1979). The most direct paths are distyly to dioecy (A), monoecy to dioecy (B) or hermaphrodism to dioecy (C), although subdioecious species with aberrant flower types may follow a more complex (D) path involving monoecy. Gynodioecious plants may have only hermaphroditic flowers on the nonpistillate (male) plants (E), males and hermaphrodites (androdioecious; $\mathbf{F}$ ), or may include both staminate and hermaphroditic flowers on the nonpistillate (male) plants $(\mathbf{G})$ depending on the definition used. show some aberrant flower types such as monoecious flowers [indicating a pathway with monoecy as an intermediate step (Fig. 1B and D)] or hermaphroditic flowers [indicating gynodioecy, andromonoecy, or androdioecy as an intermediate step (Fig. 1E-G) (Ainsworth, 2000; Pannell, 2002; Ross, 1982; Webb, 1979)]. Such outliers in dioecious species may allow for stand establishment via self-pollination in an otherwise selfincompatible species.

In tandem with dioecy, Z. americanum also uses a clonal reproductive strategy by forming clonal stands from horizontal roots (Reinartz and Popp, 1987). Whether Z. americanum also produces seed asexually-via nucellar embryony similar to citrus or otherwise - has yet to be clearly documented.

Zanthoxylum americanum has characteristics that make it of potential economic importance. Its fruit have a strong citrus scent that could be marketed in the United States and Canada as a native natural fragrance. The genus and species contain compounds that have potential for pharmacological use (Bafi-Yeboa et al., 2005; Ju et al., 2001; Patiño et al., 2011) and chemical constituents with possible insecticidal or insect repellent properties (Bowers et al., 1993; Jacobson, 1948; Maji and Hussain, 2009).

Fruit of Asian Zanthoxylum species, such as Z. bungeanum, $Z$. simulans, and $Z$. piperitum, are used as peppercorns in Sichuan and other Asian cuisines (Damery, 2011; Katzer, n.d.). A U.S. ban prevented importation of fresh peppercorns and citrus canker bacterium, Xanthomonas axonopodis pv. citri (U.S. Department of Agriculture, 2012b). This ban provided an opening in the peppercorn market for peppercorns produced directly from $Z$. americanum or by crossing $Z$. americanum with peppercorn-producing species.

Commercial use of the Z. americanum sibling genus, Citrus, faces obstacles in the United States, such as disease threats and limited areas with suitable climates. Zanthoxylum americanum may be useful in citrus disease avoidance, either as a citrus rootstock or as a genetic source for citrus disease resistance. A breeding program to incorporate genes for citrus fruit characteristics into $Z$. americanum could create a market for more coldhardy citrus, thereby expanding the citrus growing range into areas with cold climates and simultaneously avoiding citrus diseases and pests that cannot survive in cold climates or that have not attacked $Z$. americanum.

Breeding programs meant to exploit the potential of $Z$. americanum depend on the knowledge of $Z$. americanum reproduction and ways to manipulate it. Native populations of $Z$. americanum in Minnesota have never been studied to determine the reproductive barriers operating in the species. Therefore, in addition to sex determination of the studied genotypes, four objectives to study the reproductive traits were investigated to determine: 1) Pollen viability of $Z$. americanum, 2) whether autonomous apomixis was the predominant floral reproductive mechanism, 3) the 
presence of seedless fruit (parthenocarpy/stenospermocarpy), and 4) the presence of hermaphrodism.

\section{Pollen Viability}

Whether Z. americanum pollen is viable gives some indication of whether $Z$. americanum uses sexual reproduction. A high viability rate would support the premise that sexual reproduction is a primary means of reproduction in $Z$. americanum. A low viability rate would support the premise that apomixis is a primary means of reproduction in Z. americanum. Long-term pollen viability is also of interest for a $Z$. americanum breeding program, especially one involving other species because this allows for pollination outside of the normal Z. americanum blooming period.

\section{Autonomous Apomixis}

This study tests whether the fruit:flower ratios of unpollinated branches differ significantly from the fruit:flower ratio of branches pollinated by fresh Z. americanum pollen. A fruit:flower ratio on unpollinated branches greater than or equal to that of $Z$. americanum pollinated branches $\left[\mathrm{H}_{0}\right.$ (the null hypothesis) $]$ would indicate that autonomous apomixis is the predominant form of floral reproduction in $Z$. americanum as the presence of pollen would not have increased the fruit production rate. A fruit:flower ratio on $Z$. americanum pollinated branches that is significantly higher than that of unpollinated branches $\left(\mathrm{H}_{1}\right)$ would indicate that other factors such as sexual reproduction or pseudogamous apomixis play a substantial role in $Z$. americanum floral reproduction as the presence of pollen would have increased the fruit production rate.

\section{Seedless Fruit (Parthenocarpy/Stenospermocarpy)}

Seedless fruit might present clues to other aspects of $Z$. americanum floral reproduction such as whether selfing occurs. This study documents whether the $Z$. americanum study populations produce seedless fruit and, if so, whether the fruit are parthenocarpic or stenospermocarpic.

\section{Hermaphrodism}

This study documents instances of hermaphrodism found in the study populations. Pollen viability of hermaphroditic flowers from a group of hermaphroditic plants is compared with that of primarily staminate plants $\left(\mathrm{H}_{0}\right.$ : the pollen viability rates are equal; $\mathrm{H}_{1}$ the pollen viability rates are not equal). It also investigates whether fruit from hermaphroditic flowers might be the result of selfing or apomixis. Fruit that develop on branches of predominantly staminate flowered plants when pollen has been excluded from those branches would indicate that those fruit resulted from selfing or apomixis.

\section{Materials and Methods}

Study SPeCIEs. Two Minnesota $Z$. americanum populations were used in this study. One population consisted of 120 putative clonal stands found in the St. Croix Bluffs Regional Park in Washington County, MN [western-most clonal stand (lat. $44^{\circ} 47^{\prime} 41.7^{\prime \prime} \mathrm{N}$, long. $92^{\circ} 48^{\prime} 04.0^{\prime \prime} \mathrm{W}$ )]. The second population consisted of 30 individual putative clonal stands in the Cottage Grove Ravine Regional Park in Washington County, $\mathrm{MN}$ [eastern-most clonal stand (lat. $44^{\circ} 48^{\prime} 11.0^{\prime \prime} \mathrm{N}$, long. $\left.\left.92^{\circ} 54^{\prime} 10.2^{\prime \prime} \mathrm{W}\right)\right]$. The western-most St. Croix Bluffs Regional Park clonal stand studied was $8.08 \mathrm{~km}$ east-northeast of the easternmost Cottage Grove Ravine Regional Park clonal stand studied.

Individual clonal stands were identified by distinct separations (i.e., areas with no $Z$. americanum stems) of $\approx 3$ or more between sympatric plant groupings. Whether members within individual clonal stands were truly the same clones (clonal ramats) was not determined by the observation of traits other than the sex of the flower. One plant (i.e., stem rising out of the ground) from each clonal stand was tagged and numbered. Each tagged plant was then the primary member of the clone used in subsequent interactions. At times it was necessary to also use other plants from a clone, such as during the pollination studies when there were insufficient branches on the primary plant of a clone. In such cases, the nearest neighboring stem within the same clonal stand to the tagged plant was used.

Sex Determination. The sex of each tagged plant was determined in 2013 by forcing 5-10 stems into flowering indoors from each genotype. Stems were removed in mid winter 2013 (weeks 1-8); each stem was $\approx 15 \mathrm{~cm}$ long (the lengths varied depending on the location of flower buds on each stem). The stems were placed vertically (terminal bud at the top) in 532-mL cups (Kordite ${ }^{\circledR}$ ASIN B00E7FUFRM; Reynolds Consumer Products, Lake Forest, IL) filled with $100 \mathrm{~mL}$ of floral preservative solution [10 g Aquaplus ${ }^{\circledR}$ powder per liter distilled water (Aquaplus ${ }^{\circledR}$; Syndicate Sales, Indianapolis, IN)] and kept at room temperature $\left(22^{\circ} \mathrm{C} / 15^{\circ} \mathrm{C}\right.$ day/night $)$ under $\mathrm{T} 5$ fluorescent lights $[\approx 30 \mathrm{~cm}$ distance from the terminal bud to the lights (AgroBrite ${ }^{\circledR}$ T5 lights, 54W, 6400K; Hydrofarm, Petaluma, CA)] with a long-day photoperiod (0600 to $2200 \mathrm{HR}$ ). The floral preservative solution was replaced weekly.

Flowers were evaluated after budbreak when either the styles (females) or anthers (males) became apparent (Fig. 2). Sexes of the flowers on each forced stem were determined by examining all of the inflorescences/stem and categorizing them as male (staminate flowers) or female (pistillate flowers) (Fig. 2 ). The sex of each plant was later reconfirmed in situ when the tagged plants reached anthesis, May 2013 (weeks 17-20).

Pollen viability. Fresh pollen was collected in 2013 from 30 males of $Z$. americanum at anthesis (11 of these were later found to be "fruiting males") during the March-April period, forcing study from forced cuttings. Fresh pollen from the hermaphroditic group was collected in situ in May 2014. Within $1 \mathrm{~h}$ of collection, the pollen was stained with $0.1 \%$ aniline blue in $80 \%$ propionic acid and observed under a microscope (Anderson and Ascher, 2000). Viable pollen grains (stained) and nonviable pollen grains (not stained) were counted in 12 microscope fields containing at least $20+$ pollen grains.

Pollen was also prepared for long-term cold storage using established pollen storage protocols (Towil, 2010). Fresh pollen was placed in gel caps immediately after collection. The gel caps were then placed in a sealed polyethylene bag (Ziplock ${ }^{\circledR}$ Gallon Storage, $26.8 \times 27.3 \mathrm{~cm}$; S.C. Johnson \& Son, Minneapolis, MN) containing Drierite ${ }^{\circledR}$ desiccant (W.A. Hammond Drierite Co., Xenia, $\mathrm{OH}$ ) and kept in the plastic bag for $24 \mathrm{~h}$ at room temperature $\left(22^{\circ} \mathrm{C} / 15^{\circ} \mathrm{C}\right.$ day/night $)$. The gel caps with pollen were then transferred to a freezer for long-term cold 


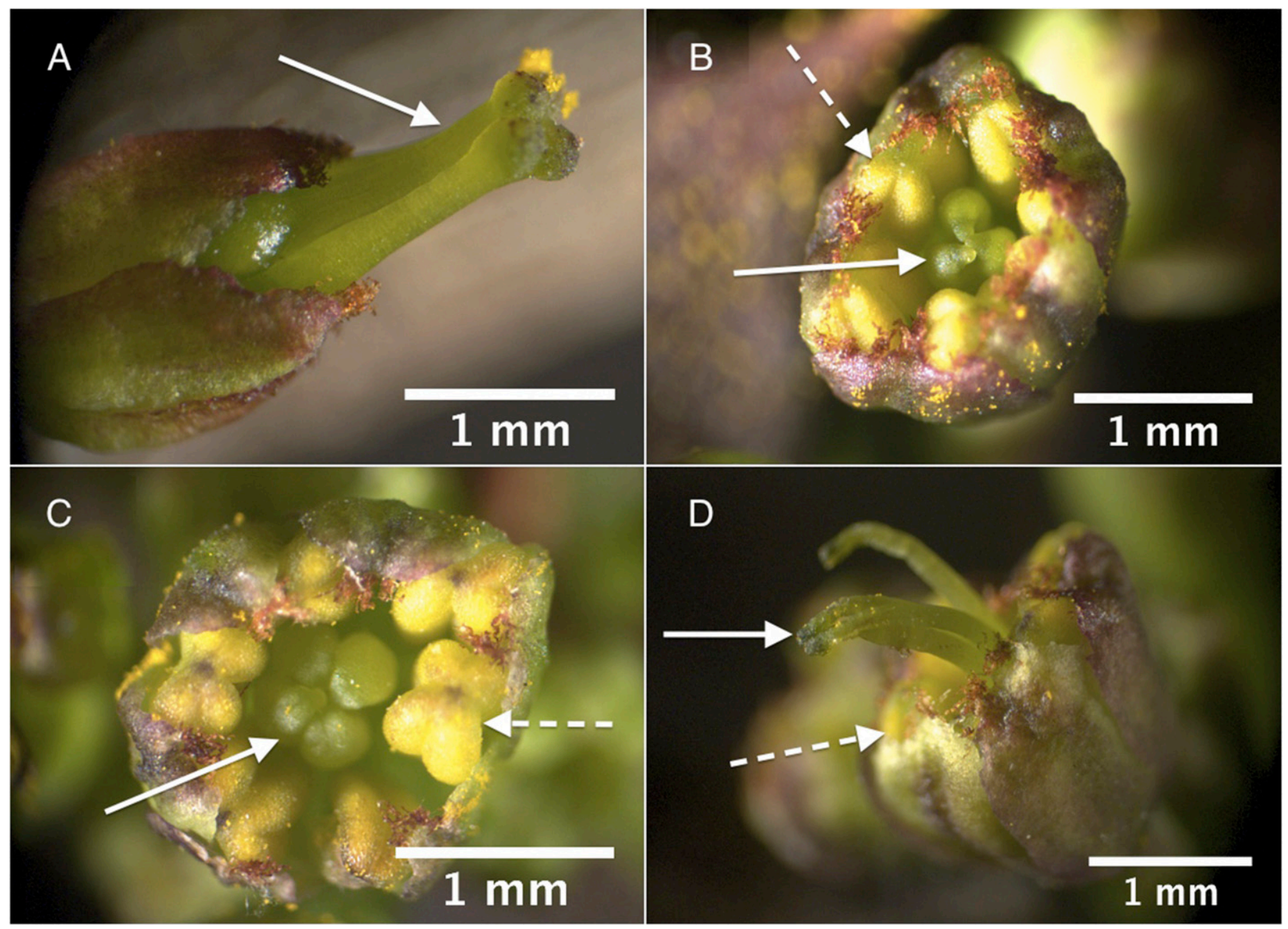

Fig. 2. Flowers of Zanthoxylum americanum sexual variants: (A) Flower from a pistillate plant. Styles (solid arrow) are relatively thick with somewhat bulbous stigmas; pollen (yellow) is adhering to a stigma. (B) Flower from a male that did not produce fruit. Pistil development is minimal (solid arrow). Anthers are approaching anthesis (dashed arrow). (C) Flower from a fruit-producing male (i.e., plant with predominately staminate flowers). Anthers (dashed arrow) are approaching anthesis but pistil development (solid arrow) is minimal. (D) Hermaphroditic flower from a plant (hermaphroditic group) that had both hermaphroditic and staminate flowers. The stigmas/styles (solid arrow) emerged before the anthers (dashed arrow) reached anthesis. Styles and stigmas appear malformed, with thin styles and nonbulbous stigmas. Some pollen (yellow) is present on the styles and stigmas.

storage at about $-12{ }^{\circ} \mathrm{C}$. Once each month, a sample of the stored pollen was removed from the cold storage. Pollen from the sample was evaluated for viability using the same methodology as for fresh pollen.

Pistils were placed in FAA [1 formalin : 1 acetic acid : 8 ethanol, v/v (Martin, 1959; Gardner et al., 2009)] under refrigeration until analyzed. Pistils were removed from the FAA and placed in $8 \mathrm{~N} \mathrm{NaOH}$ for 45 min to soften the styles (Gardner et al., 2009; Kho and Baer, 1968). The pistils were removed from $8 \mathrm{~N} \mathrm{NaOH}$, rinsed with deionized water $\left(\mathrm{dH}_{2} \mathrm{O}\right)$, and then soaked in $\mathrm{dH}_{2} \mathrm{O}$ for $1 \mathrm{~h}$. The pistils were removed from $\mathrm{dH}_{2} \mathrm{O}$ and placed in decolorized aniline blue $(0.05 \%$ aniline blue, $65 \mathrm{~mm} \mathrm{Na}_{2} \mathrm{HPO}_{4}$ ) for at least $1 \mathrm{~h}$. After treatment with decolorized aniline blue, the pistils were removed from the aniline blue solution and placed on microscope slides, using drops of the aniline blue solution as needed to fill the gaps under the microscope slide coverslip. The slides were microscopically observed for pollen germination and tube growth with an ultraviolet light source and filter (Gardner et al., 2009).

Autonomous Apomixis. Reproductive biology studies for this objective, seedless fruit (parthenocarpy/stenospermocarpy), as well as hermaphrodism all had interrelated methods to document the occurrence of each phenomenon. In 2013, stems were forced into flowering during weeks 9-16 using the technique described above. Zanthoxylum americanum pollen was collected from forced cuttings for use in this study. Pollen was applied using a small paintbrush a random number of days after style elongation $(0-5 \mathrm{~d}$ because the time from style elongation to stigma receptivity was not known). The Microsoft Excel $^{\circledR}$ (Excel 2016, version 14.7.2; Microsoft Corp., Redmond, WA) Rand function was used to generate random numbers for pollination days. Style elongation was visually identified when styles began to separate within inflorescences. Styles within a $Z$. americanum inflorescence emerge from the flower bud in a fused state, elongate, and then spread apart (Fig. 2A). The stigmas come back together and fuse late in the blooming cycle.

Separate camel hair pollination brushes were used for each Z. americanum pollen type and were dipped in $70 \%$ ethanol and air dried between pollinations. Pollinated flowers were removed from the stems $3 \mathrm{~d}$ postpollination with tweezers and placed in FAA. 
In situ pollinations (outdoors) were conducted on wild $Z$. americanum plants at the Cottage Grove Ravine (CGR) and St. Croix Bluffs (SCB) locations. Eight branches per tagged female plant were bagged with $45.7 \times 40.6-\mathrm{cm}$ pollination bags (no. 310023-1; DelStar Technologies, Middletown, DE) and randomly assigned one of two treatment types, with two of each treatment type replicated/female. In cases where the tagged females did not have eight branches, adjacent plants that appeared to be part of the same clone (same plant grouping) were included in the bagging. Each bag was sealed with a colorcoded clothespin that indicated its treatment type.

These in situ pollinations were done in a 5-d period in week 20 because the female plants did not flower on the same day. Each bag was briefly removed from its branch, flowers were counted, pollinated, and then the bag was placed back on the branch. This was done one bag at a time to minimize the length of time for potential pollen exposure. Pollinations were performed in the following order, and all pollinations of the same treatment type were done before moving onto the next treatment type to prevent accidental contamination with the wrong pollen type for all plants: 1) no pollen-the flowers were counted; half of the bagged portion of the branch was stimulated with an empty artist's paintbrush to simulate pollination contact without pollen being present; no stimulation and no pollination were done to the remaining flowers on the bagged portion of the branch; 2) $Z$. americanum pollen-the flowers were counted and then a mixture of $Z$. americanum pollen (bulked in $\approx$ equal amounts from the tagged males in flower) was applied with a paintbrush. Specific plants (SCB034, SCB035, SCB039, SCB042, SCB043, SCB044, SCB045, SCB048, SCB054, SCB057, and SCB060) were also checked for autonomous apomixis with an additional "no pollen" treatment wherein the bags were not removed and the flowers received no stimulation; the bags were never removed until flowering finished, serving as an added control in the case of pollen contamination when other bags were briefly removed during pollination.

Pollination bags were kept on the branches for 3 weeks after pollination to prevent pollen contamination. Fruit on each of these branches were counted in weeks 21-25 (2013) and, again, just before harvest. The harvest date [weeks 32-34 (2013)] for each plant was determined when the fruit color changed from green to red. All fruit on a given plant were harvested within a 2-d period rather than waiting for all fruit to ripen because the seeds were ejected from well-ripened capsules. Harvested fruit were placed in paper bags labeled with the plant identification (ID) and bagged branch type, kept at room temperature $\left(22^{\circ} \mathrm{C} /\right.$ $15{ }^{\circ} \mathrm{C}$ day/night) until dry, after which the seeds were cleaned and counted. Fruit:flower ratios were determined.

"Fruiting males" (i.e., plants that bore fruit although they initially had only staminate flowers) were discovered serendipitously in the study populations. Since the discovery happened late in the blooming period of 2013, investigations concerning the "fruiting males" were limited to documenting the presence or absence of fruit on each tagged male in the study populations. Every branch of each tagged male was visually inspected for developing fruit in weeks 22-24. The same visual inspections were conducted again at harvest time and any fruit on those males were then harvested.

Research objectives in 2014 were to: 1) confirm autonomous apomixis in Z. americanum and 2) control for selfing or apomixis in "fruiting males." Female parents in 2014 were limited to plants that showed potential apomixis in 2013. Pollination bags were placed on branches before budbreak with bags on most of the branches of the entire clonal stand, not just the tagged plant. Pollination bags were randomly assigned treatment types: 1) no pollination (as both a control and to control for autonomous apomixis) and 2) bulked Z. americanum pollen. Pollination was performed when most styles on a given clonal stand reached the elongation stage. The 2014 flowering spanned a 2-week period, with some clonal stands flowering earlier, whereas others flowered later in the period. Pollinations used the same methodology as in 2013.

Because possible unintended pollinations may have occurred during 2013 while the bags were briefly removed to count the flowers, the methodology for the unpollinated controls was modified in 2014. Double bagging of unpollinated branches was used in 2014 to ensure isolation of the bagged branches from extraneous pollen and to determine whether fruit would appear without outcrossing pollen (i.e., whether selfing or apomixis might be involved in male fruit production). For double bagging, a branch was sealed within one bag, which was then sealed within a second bag. In 2014, flowers were counted for the unpollinated controls after each clonal stand finished flowering when the styles were beginning to drop off the pistils (i.e., flowers were counted after flowering finished but before flower remnants fell off the plants). As some flowers could have dropped off into the pollination bags during that time, dried flowers in the bags were included in the no-pollen flower counts. Flower counts were, therefore, likely lower for these unpollinated branches than the actual number of flowers on those branches, meaning that fruit-to-flower ratios were likely less than reported here.

To test whether the technique of Desai (1962) in a previous $Z$. americanum apomixis study would give different results, six of the unpollinated control bagged branches from one large clonal stand were used to emulate the Desai treatment. The stigmas and styles were manually removed from six unpollinated bagged branches so that no stigmatic pollinations could occur, and the bags were then immediately placed back over those branches. Bags were removed three weeks after all male flowering had finished. For "fruiting males" in 2014, only the two males with the largest 2013 fruit crop (plants CGR023 and SCB041) were chosen for bagging studies. Six branches were bagged on each of those two males before budbreak. The same methodology was followed for these bags as was used for the 2014 nonpollination controls (see above).

SEEDLESS FRUIT (PARTHENOCARPY/STENOSPERMOCARPY). Fruit from pollinations conducted in both 2013 and 2014 were analyzed for the presence of parthenocarpy and stenospermocarpy. The female fruit clusters were examined for smaller sized fruit. If these were found, the status of the embryo or seed was determined (aborted and nonaborted).

Hermaphrodism. Hermaphrodism was not studied in 2013 because it was not known this was a phenomenon until the end of 2013, when fruit appeared on some plants identified with male flowers. The presence of hermaphrodism was evaluated in 2014. Flowers were examined in all genotypes of the populations for specific hermaphroditic flower types: 1) pistillate flowers with no stamens, 2) functionally staminate flowers with fully developed anthers and rudimentary pistils, and 3) hermaphroditic flowers containing fully developed stamens as well as fully developed pistils. The presence of hermaphroditic plants $( \pm)$ was recorded. 
Statistical analysis. Pollen viability data were analyzed using Microsoft Excel $^{\circledR}$ (Excel 2016, version 14.7.2) and StatPlus:mac ${ }^{\circledR}$ (version 3/4; AnalystSoft, Alexandria, VA) except for analysis of variance and Tukey's honestly significant difference tests at $\alpha=0.05$, which were conducted via SPSS ${ }^{\circledR}$ (version 24; IBM Corp., Armonk, NY). Stainability ratios were arcsin, square root transformed before analyses because of the lack of normality. Fruit:flower ratio comparisons of unpollinated flowers vs. Z. americanum pollinated flowers were conducted using Microsoft Excel ${ }^{\circledR}$ and the associated statistical package StatPlus: $\mathrm{mac}^{\circledR}$. Because of the lack of normality, fruit:flower ratios were arcsin, square root transformed before being used in paired $t$ tests.

\section{Results}

Sex determination. The CGR population consisted of 12 females and 18 males (40\% females and 60\% males), whereas the SCB location consisted of 73 females and 42 males $(63.5 \%$ females and $36.5 \%$ males). There were 85 females and 60 males (58.6\% females and $41.4 \%$ males) in the combined populations (the remaining five plants did not produce flowers).

Pollen Viability. Fresh pollen had a grand mean viability of $95.8 \% \pm 0.3 \%$, with genotype differences accounting for most of the variance (Table 1). Plant CGR011 had significantly lower pollen stainability than all other populations except that it overlapped with CGR015 (Table 1). During 1-9 months of storage at $-12{ }^{\circ} \mathrm{C}$, pollen viability had significant variation, whereas the subsequent samplings (10-18 months) were less variable, centered mainly at $\approx 80 \%$ stainability (data not shown). By the end of the 18-month storage period, pollen viability had decreased to $78.6 \% \pm 1.1 \%$ (data not shown)nearly $20 \%$ less than fresh pollen.

Pollen viability tests conducted on pollen from hermaphroditic flowers indicated a high degree of viability, ranging from $95.1 \%$ to $100 \%$ in the samples tested. Fresh pollen viability rates were $95.8 \% \pm 0.3 \%$ for all males, $96.1 \% \pm 0.4 \%$ for "fruiting males," $95.6 \% \pm 0.4 \%$ for non-"fruiting males," and $98.7 \% \pm 0.4 \%$ for the hermaphroditic group (Table 1). Pollen viabilities of the male groups were significantly different from the pollen viability of the hermaphroditic group (Table 1).

Autonomous Apomixis. In 2013, 38.9\% of the branches that were unpollinated with the bag removed during flowering produced fruit (Table 2) with a mean fruit count of $11.9 \pm 1.2$ and a median fruit count of 4.0 for those branches bearing one or more fruit (data not shown). The fruit:flower ratio for unpollinated branches was $6.2 \% \pm 1.7 \%$ (Table 2 ). Oddly enough, a higher percentage of bagged branches with fruit $(59.1 \%$, Table 2$)$ occurred when the bags were not removed. By contrast, $85.6 \%$ of the branches pollinated with $Z$. americanum pollen (the control group) had one or more fruit (Table 2), with a mean fruit count of $33 \pm 3.2$ and a median of 23 fruit for the branches that bore fruit (data not shown). The fruit:flower ratio for this control group was $46.5 \% \pm 5.3 \%$ (Table 2). Fruit:flower ratios for $Z$. americanum pollinated branches were significantly different $(P<0.05)$ from the fruit:flower ratios of unpollinated branches.

In $2014,15.3 \%$ of the unpollinated branches had one or more fruit (Table 2), with a mean fruit count of $1.6 \pm 0.1$ and a median fruit count of 1.0 for those branches bearing one or more fruit. The fruit:flower ratio was $0.3 \% \pm 0.0 \%$ (Table 2 ). None of the unpollinated, cropped treatment bore any fruit (Table 2). By contrast, $91.3 \%$ of the branches pollinated with $Z$. americanum

Table 1. Pollen stainability (stained with $0.1 \%$ aniline blue in $80 \%$ propionic acid) of freshly collected pollen collected from Zanthoxylum americanum males in two Minnesota populations and data pooled by all males sampled, non-"fruiting males" sampled, "fruiting males" sampled, and the hermaphroditic group. Data are the mean values of 12 replicates (microscope fields with $\geq 20$ pollen grains/field).

Accession code $\quad$ Pollen stainability [mean \pm SE (\%)]

Cottage Grove Ravine (CGR) population

CGR001

CGR002

CGR003

CGR005

CGR009

CGR010

CGR011

CGR015

CGR016

CGR023

CGR025

CGR026

CGR027

CGR029

Pooled

St. Croix Bluffs (SCB) population

SCB001

SCB002

$\mathrm{SCB} 003$

SCB004

SCB005

SCB006

SCB015

SCB016

SCB027

SCB053

SCB058

SCB095

SCB097

SCB104

SCB112

SCB113

Pooled

All males sampled

Non-"fruiting males" sampled

"Fruiting males" sampled

Hermaphroditic group

${ }^{\bar{z}}$ Values followed by different letters were significantly $(P<0.05)$ different, based on Tukey's honestly significant difference test.

pollen had one or more fruit (Table 2), with a mean fruit count of $39.5 \pm 10.9$ and a median of 29 fruit for the fruiting branches. The fruit:flower ratio for this control group was $56.2 \% \pm 11.5 \%$ (Table 2).

SEEDLESS FRUIT (PARTHENOCARPY/STENOSPERMOCARPY). No instances of true parthenocarpy were observed in the study populations. Stenospermocarpy was common in the study populations (Fig. 3), with one or more stenospermocarpic fruit occurring in $13 \%$ of the female fruit clusters examined (Fig. 4). Stenospermocarpic fruit were much smaller than normal, seedcontaining $Z$. americanum fruit, but varied in size (Figs. 4 and 5). Stenospermocarpic fruit size was relative to the size of the remnant aborted seed inside. 
Table 2. Bagged branches, bagged branches with fruit, flowers, fruit, bagged branches with fruit, and fruit:flower ratio $(\times 100)$ for in situ 2013 and 2014 pollination treatments of Zanthoxylum americanum crosses.

\begin{tabular}{|c|c|c|c|c|c|c|}
\hline Treatments & Bagged branches (no.) & $\begin{array}{l}\text { Bagged branches } \\
\text { with fruit (\%) }\end{array}$ & Flowers (no.) & Fruit (no.) & $\begin{array}{l}\text { Bagged branches } \\
\text { with fruit }(\%)\end{array}$ & $\begin{array}{c}\text { Fruit:flower } \\
\text { ratio }(\% \pm \mathrm{SE})\end{array}$ \\
\hline \multicolumn{7}{|l|}{2013} \\
\hline $\begin{array}{l}\text { Not pollinated, bag removed } \\
\text { during flowering }\end{array}$ & 90 & 35 & 6,759 & 417 & 38.9 & $6.2 \pm 1.7$ \\
\hline $\begin{array}{l}\text { Not pollinated, bag not } \\
\text { removed during flowering }\end{array}$ & 44 & 26 & $\mathrm{~N} / \mathrm{A}^{\mathrm{z}}$ & 296 & 59.1 & $\mathrm{~N} / \mathrm{A}^{\mathrm{z}}$ \\
\hline Z. americanum & 90 & 77 & 5,460 & 2,538 & 85.6 & $46.5 \pm 5.3$ \\
\hline Not pollinated & 59 & 9 & 4,110 & 14 & 15.3 & $0.3 \pm 0$ \\
\hline Not pollinated, cropped & 6 & 0 & 374 & 0 & 0.0 & 0.0 \\
\hline Z. americanum & 23 & 21 & 1,476 & 829 & 91.3 & $56.2 \pm 11.5$ \\
\hline
\end{tabular}

${ }_{\mathrm{Z}}^{\mathrm{N}} / \mathrm{A}=$ no counts were made because the bags were not removed.
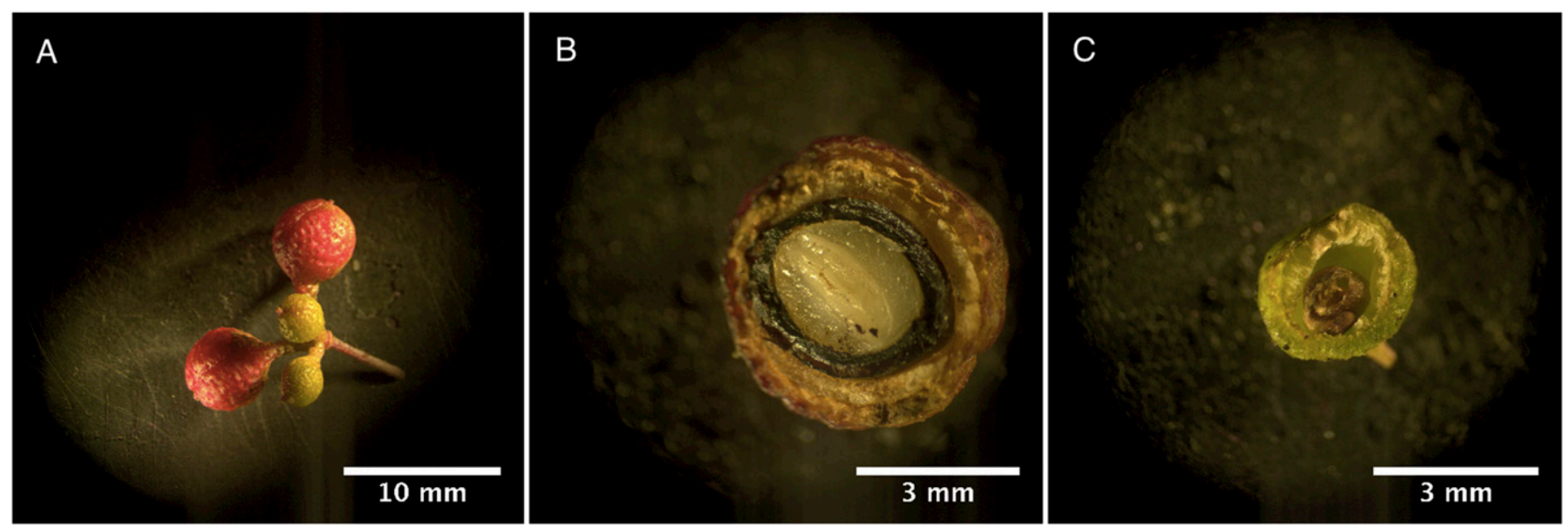

Fig. 3. (A) A Zanthoxylum americanum fruit cluster containing both fully developed fruit and the smaller stenospermocarpic fruit. (B) A cross-section of a fully developed fruit. The seed fills the entire fruit cavity. (C) A cross-section of a stenospermocarpic fruit. The aborted seed remnant is shriveled and fills only a portion of the seed cavity.

Hermaphrodism. Three flower types were identified in the populations: 1) pistillate flowers with no stamens, 2) functionally staminate flowers with fully developed anthers and rudimentary pistils, and 3) hermaphroditic flowers containing fully developed stamens as well as fully developed pistils. The flowers occurred on four sexual variants (Fig. 2): A) females (i.e., plants with only pistillate flowers), B) non-"fruiting males" (i.e., plants with only functionally staminate flowers observed and producing no fruit), C) "fruiting males" (i.e., plants that appeared to have only functionally staminate flowers but yet produced fruit), and D) one hermaphroditic group of plants (possibly one clonal stand) with both hermaphroditic and functionally staminate flowers on the same plant.

In $2013,30 \%$ of the males $(18 / 60$ males in the combined study populations) bore at least one fruit. The mean fruit count was $14.9 \pm 6.5$ per fruiting male, with a median fruit count of 4.5. Two outliers, one of which bore more fruit than all of the other males combined, skewed the mean (data not shown). The most productive male genotype bore $>100$ fruit. By contrast, female plants often bore more than 1000 fruit per plant (data not shown). Fruit clusters on "fruiting males" never exceeded five fruit/cluster with a high incidence of stenospermocarpic fruit; females typically bore fruit in clusters exceeding 20 fruit.
In 2014, the fruit production rate in male plants dropped to $10 \%$ of males (6/60 males in the combined study populations) bearing at least one fruit. The mean fruit count was $4.2 \pm 1.6$ fruit per fruiting male with a median fruit count of 2.5. Fruit sometimes set on the same branches as in 2013, but in no case did fruit appear at the same location (same axillary cluster location) in both years. Fruit appeared in seemingly random locations on the plants except that in 2013 fruit were often observed just below the site where cuttings were taken in the winter of 2013 (Fig. 5).

Based on remnant flower parts when the male fruit were first observed, flowers in fruit-bearing flower clusters on male plants had both hermaphroditic and staminate flowers (Fig. 6). Flower remnants on male fruit-bearing branches were staminate other than the hermaphroditic fruit-bearing flowers. Staminate flowers appeared both acropetally and basipetally to the fruitbearing flowers (Fig. 6).

In 2014, male fruit appeared only on male plants that bore fruit in 2013. The highest male fruit producer from 2013 (plant ID CGR023) did not bear any fruit in 2014. Genotype CGR023 is in the CGR population, where 2014 fruit production was very low. Four CGR males bore fruit in 2013 (including the top male fruit producer, CGR023), but no CGR males bore fruit in 2014. 

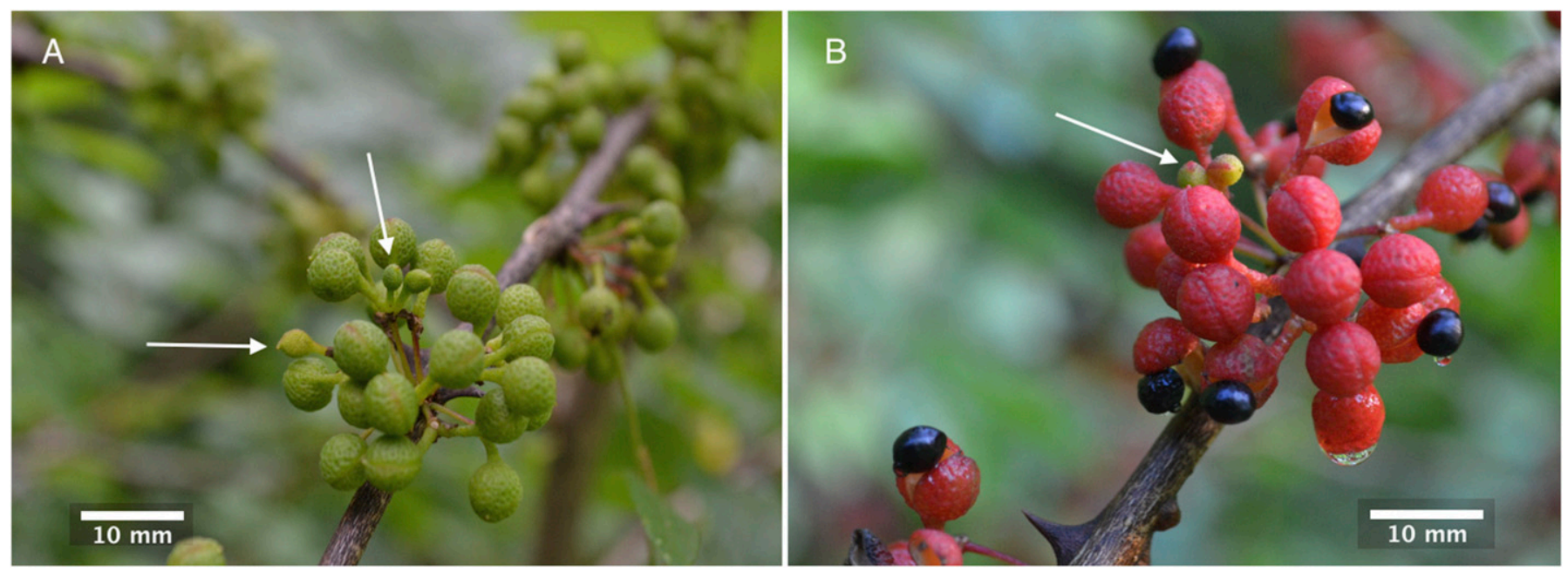

Fig. 4. Fruit clusters from pistillate Zanthoxylum americanum plants. (A) The clusters contain both normally developing fruit (larger fruit) and stenospermocarpic fruit [smaller fruit (arrows)]. (B) At ripening time, stenospermocarpic fruit (arrow) were often still green when the rest of the fruit in the same cluster were red.

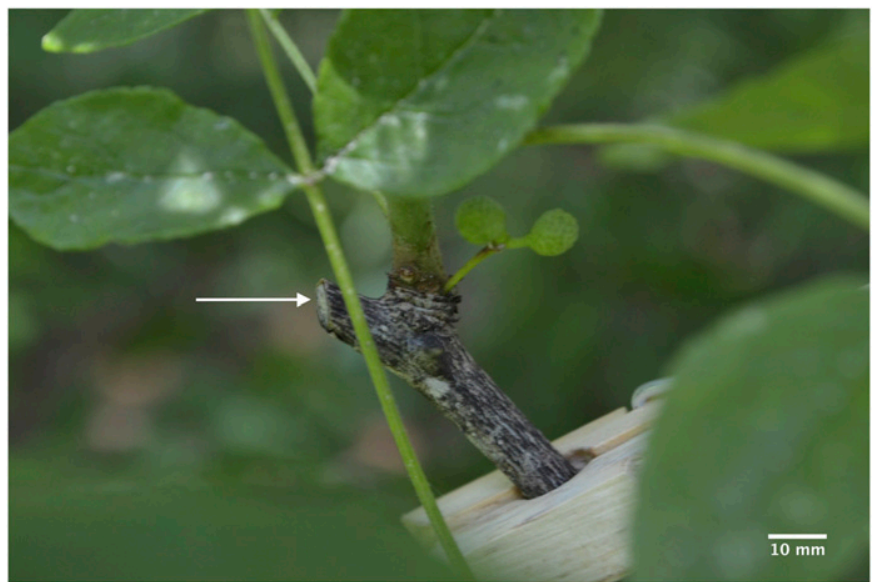

Fig. 5. Fruit developing on a male (predominantly staminate) Zanthoxylum americanum plant. The fruit cluster is adjacent to the cut end of the branch (arrow). Note that the number of fruit is substantially less than observed pistillate plants (see Fig. 4).

Plant ID CGR023 was one of the two males involved in the 2014 bagging study. One of the bagged branches on the other 2014-bagged male (plant ID SCB041) did produce fruit.

Stigmas and styles on hermaphroditic flowers from the hermaphroditic group (Fig. 2D) appeared somewhat misshapen compared with stigmas and styles on female plants (Fig. 2A). The stigmas on these hermaphroditic flowers were protogynous, extending above the anthers before the anthers reached anthesis. By contrast, the staminate flowers were protandrous, with the anthers developing before the pistils and with pistil development often minimal; pistil development was delayed in the staminate flowers with pistils still incomplete at anthesis. Pollen germination occurred on pistillate flowers (Fig. 7A) and, despite their misshapen appearance, stigmas on the hermaphroditic flowers were also able to support pollen germination (Fig. 7B).

Despite a relatively large number of hermaphroditic flowers in the hermaphroditic group, only thirteen fruit developed on the seven plants. This may be explained, in part, by hermaphroditic samples removed from plants, but even areas of the plants, which were not sampled (i.e., the top of the canopy), had low fruiting rates.

\section{Discussion}

Pollen viability. The high fresh pollen viability and vigorous pollen germination visible under fluorescence (Fig. 7) indicate that pollen can play a role in Z. americanum floral reproduction in these populations via either sexual crosses or pseudogamous apomixis (pollination that does not involve male inheritance) because both require viable pollen and pollen germination. Pollen viability could be expected to decline during $Z$. americanum evolution if autonomous apomixis were the driving reproductive force because pollen would no longer be needed for reproduction. The high rate of males in the study populations $(41.4 \%$ males for the combined populations) implies that sexual reproduction continues in this species, unless there is a facet of sex determination in Z. americanum that could otherwise account for the presence of males in the species. Likewise, environmental effects on the occurrence of males over years and locations (populations) are unknown and should be the focus of additional research.

The stored pollen viability rate might have been higher if storage conditions were colder and drier than the $-12{ }^{\circ} \mathrm{C}$ temperature used in this study (Towil, 2010). A previous collection of $Z$. americanum pollen that was stored at $-18{ }^{\circ} \mathrm{C}$ still had a viability rate of $87.5 \% \pm 1.6 \%$ after 30 months (D.A. Munter, unpublished data) compared with $78.6 \% \pm 1.1 \%$ for pollen stored for 18 months at $-12{ }^{\circ} \mathrm{C}$ in the present study (data not shown). However, pollen in the earlier study (D.A. Munter, unpublished data) came from different plants, years, and environmental conditions than the pollen used in this study, so the results may not be directly comparable. Regardless, $Z$. americanum pollen viability remains above $50 \%$ for a lengthy period of time. Breeders could store pollen for use in pollinations the following year.

Autonomous APOMIXIs. The substantially different fruit:flower ratios between $2013(6.2 \% \pm 1.7 \%)$ and $2014(0.3 \% \pm 0 \%)$ for the unpollinated branches could be an indication that the single bagging method used in 2013 did not exclude all extraneous pollen or that the branches were contaminated with extraneous 


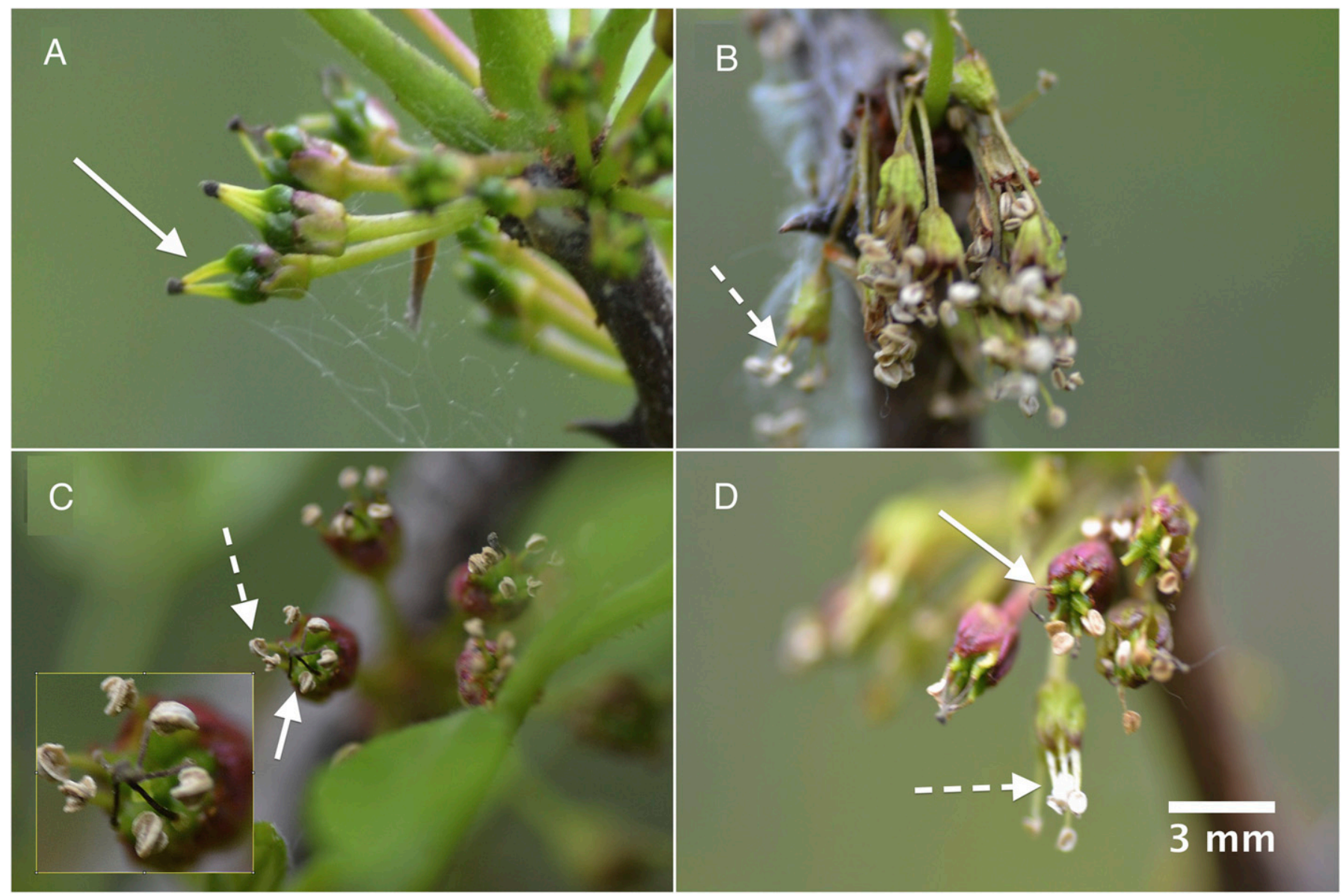

Fig. 6. Floral remnants on Zanthoxylum americanum shortly after flowering. (A) Fruit developing on a female (pistillate) plant. The stigmas/styles (solid arrow) have fused and fruit are developing. (B) Staminate flowers postanthesis (dashed arrow) are shriveled and dehiscing. (C) Remnants of hermaphroditic flowers on a predominantly male (staminate) plant; anther remnants (dashed arrow) are still attached to the flower. Remnant styles/stigmas (solid arrow) show that the stigmas had fused. Fruit have started developing (green portion of the flowers). Inset shows close-up view of remnant anthers and remnant fused styles. (D) Axillary cluster containing both hermaphroditic flower remnants [fruit have started developing — green (solid arrow)] and a staminate flower remnant [flower is shriveled and beginning to dehisce (dashed arrow)].
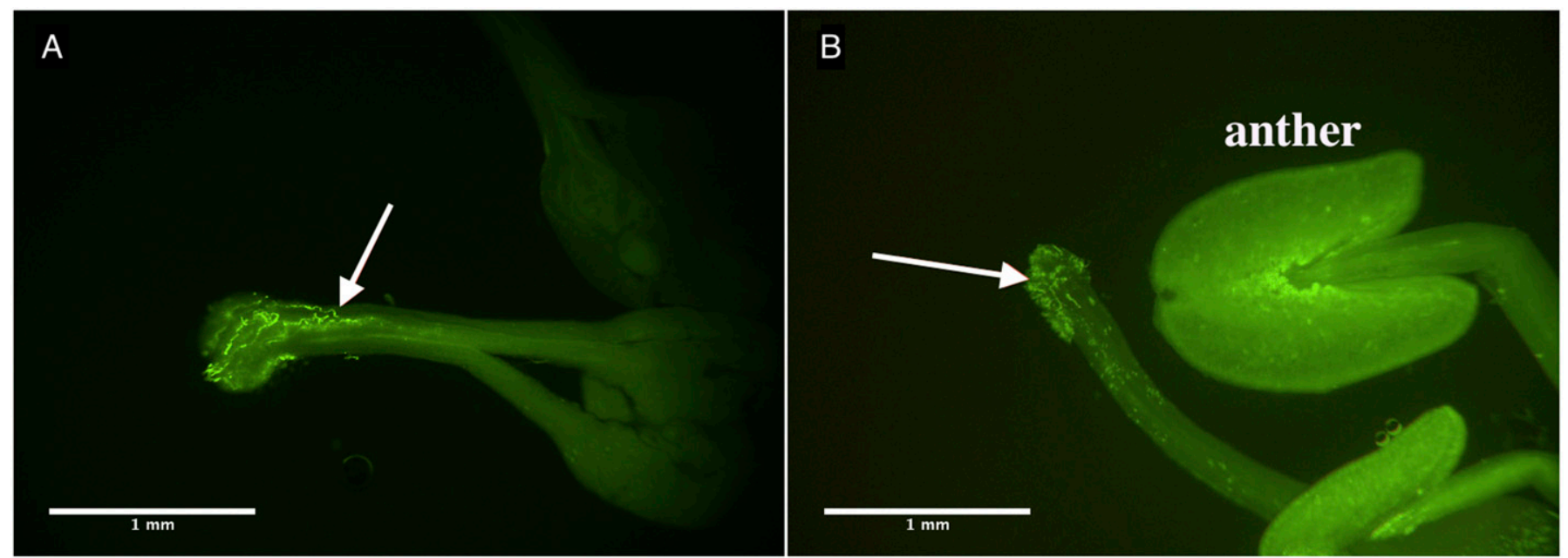

Fig. 7. Pollen germinating on stigmas and styles of Zanthoxylum americanum: (A) Stigma and style from a pistillate flower (Z. americanum pollen). Pollen has germinated and pollen tube growth is noted into the top of the style. (B) Stigma and style from a hermaphroditic flower (assumed to be $Z$. americanum pollen). Arrows indicate germinating pollen/pollen tubes on stigmas/styles, although growth of pollen tubes into the style has not occurred. 
pollen during bag removal. If either scenario is true, then the actual 2013 autonomous apomixis rate may have been substantially less than the 2013 observed rate of $6.2 \% \pm 1.7 \%$. Regardless, the presence of autonomous apomixis complicates the derivation of hybrids in a breeding program.

If autonomous apomixis was present in the $Z$. americanum study populations, the upper limit (at least on the unpollinated branches) for nonaborted fruit was the 2013 fruit:flower ratio of $6.2 \% \pm 1.7 \%$. This is contrary to a previous study where only autonomous apomixis was observed in a population consisting of only pistillate flower types (Desai, 1962).

Nonautonomous apomixis (pseudogamy) might also be present in Z. americanum. Other Zanthoxylum and some citrus species can reproduce via nucellar embryony, which is a form of apomixis that is often polyembryonic (Desai, 1962; Naumova, 1992; Yinghong et al., 1987) and may require fertilization of a zygotic embryo in order for the apomictic embryo to develop (Koltunow, 1993; Koltunow et al., 1995). In nucellar embryony in citrus, one or more embryos arise from nucellar tissue, and often one or more zygotic embryos arise from sexual union of the maternal and paternal gametes. The zygotic embryos in these cases usually die, leaving only the nucellar embryos (Koltunow, 1993; Koltunow et al., 1995). The rate for apomixis in intraspecific Z. americanum crosses has an upper bound of $46.5 \% \pm 5.3 \%$ (2013) and 56.2\% $\pm 11.5 \%$ (2014) using the fruit: flower ratio for such crosses as the upper bound (Table 2).

SEEDLESS FRUIT (PARTHENOCARPY/STENOSPERMOCARPY). Stenospermocarpic fruit size may indicate when embryo abortion took place. Early abortion would result in small fruit and later abortion producing larger fruit. Why the stenospermocarpic fruit appeared at high rates in the male fruit clusters is unclear. Some possibilities are that the pistils were not fully functional or that the aborted embryos resulted from selfing and so exhibited the effects of inbreeding depression. Further research is needed to answer these questions.

Hermaphrodism. Zanthoxylum americanum is considered a dioecious species, but reports of hermaphrodism in $Z$. americanum go back to at least 1898 (Felter and Lloyd, 1898). This dichotomy may stem from a low rate of hermaphrodism in the species, with the predominant form being dioecious but having occasional, aberrant hermaphroditic flowers. This same dichotomy exists in the Minnesota populations studied herein.

One marked aspect of hermaphrodism in the study populations is its randomness. Hermaphroditic flowers appeared sporadically and their location varied between 2013 and 2014. Even on plants that had a high incidence of hermaphrodism, hermaphroditic flowers appeared to be randomly distributed on the branches. This suggests that hermaphrodism in the study populations is controlled both genetically (only males had hermaphroditic flowers) and environmentally (random appearance on branches and inconsistent hermaphrodism in axillary clusters that previously produced fruit).

The rare and sporadic appearance of fruit (and by extension, hermaphroditic flowers) on males and the apparent lack of stamens/anthers on any female plants provide clues to the evolutionary pathway to dioecy taken by Z. americanum (Fig. 8). This observation suggests a pathway of hermaphrodite-gynodioecious-dioecious (Ross, 1982; Fig. 1E). The sporadic appearance of hermaphroditic flowers gynodioecy vs. (B) andromonoecy. on male plants but never on female plants suggests that this pathway could be further refined to hermaphrodite-gynodioeciousgynodioecious/andromonoecious, with the current gynodioecious/andromonoecious (subdioecious) state possibly on an evolutionary path toward complete dioecy (Fig. 8A). An alternative path (Fig. 8B) that involves andromonoecy is hermaphrodite-andromonoecious-gynodioecious-dioecious (Webb, 1979). This alternate path could also account for the floral types exhibited in the $Z$. americanum study populations.

A direct path from hermaphrodism to dioecy is unlikely because it would require two simultaneous mutations: 1) male sterility to give pistillate plant types and 2) loss of pistil development/functionality to give staminate or andromonoecious plant types (Ainsworth, 2000; Ross, 1982). Alternatively, perhaps these mutations could have arisen simultaneously but separately in disparate parts of the population then converged over time.

Assuming that the pistillate plant type and the andromonoecious plant type developed sequentially, one scenario (Fig. 8A) is that: 1) a mutation arose in a hermaphroditic ancestor, conveying male sterility and resulting in a mixed population of pistillate plants and hermaphroditic plants (i.e., gynodioecy) and 2) mutation(s) that damaged or delayed pistil development in nonpistillate plants resulted in a population of pistillate and andromonoecious plants (Ross, 1982). The final step would be the gradual elimination of hermaphroditic flowers, which may still be progressing (Ross, 1982). In an alternative scenario (Fig. 8B), the intermediate steps are essentially flipped, with the andromonoecious plant type appearing first, followed by the pistillate plant type (Webb, 1979). Occasional hermaphrodism may have been retained by $Z$. americanum because it conveys some benefit to the species.

Bcause the hermaphroditic flowers in the hermaphroditic group found in the study populations were protogynous and the staminate flowers were protandrous, it may be that protogyny and protandry play a role in the evolution toward dioecy in $Z$. americanum. One scenario is that balanced pistil/stamen development in ancestral $Z$. americanum hermaphroditic flowers gradually gave way to increasingly protandrous flowers, resulting in andromonoecious plants that were increasingly functionally staminate (Webb, 1979). Another plausible explanation is heterodichogamy, a reproductive barrier wherein two genetically reciprocal floral morphs temporally exhibit female or male functions within a population (Watanabe et al., 2016). With this barrier, a plant could function as a female and then, later, as a male or vice versa. Because fruit set shifted over years within the same genotypes, this may be a possibility. Further research over years would be required to extensively study whether heterodichogamy exists in these populations or others elsewhere.

As observed in the study populations, any given nonpistillate $Z$. americanum plant might fall somewhere in a range from being completely hermaphroditic to being completely staminate; only those plants lying somewhere between the two

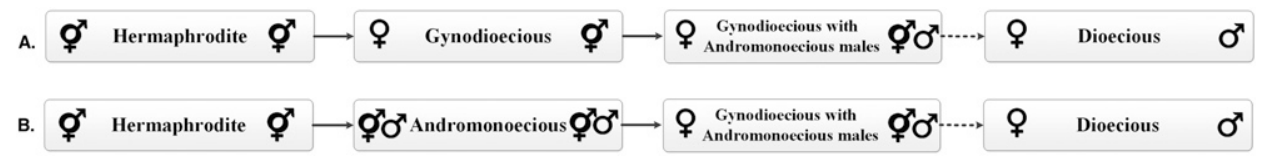

Fig. 8. Two possible Zanthoxylum americanum pathways to dioecy, which vary for the second phase: (A) 
extremes might therefore be considered andromonoecious. If there is an environmental or temporal component to the presence or absence of hermaphroditic flowers on nonpistillate $Z$. americanum plants, then any given nonpistillate plant might also hover between hermaphroditic/andromonoecious/staminate states from year to year, depending on the environmental influences on that plant.

From a breeding perspective, the apparent environmental role in hermaphroditic flower development may allow breeders to purposely induce hermaphrodism in $Z$. americanum. One key may be the variable rate of pistil development, ranging from full development in pistillate and hermaphroditic flowers to varying degrees of pistil development in staminate flowers (ranging from barely discernable pistil primordia to nearly fully developed pistils). The varying degrees of pistil development in male $Z$. americanum flowers suggest a developmental race. Anther dehiscence in $Z$. americanum may signal floral abscission (van Doorn and Stead, 1997). Pistils that develop embryos before anthers reach anthesis may be able to halt abscission and so be able to develop their fruit to maturity. If this scenario is true, treating flowers on male $Z$. americanum plants with gibberellins or other chemicals known to feminize staminate flowers in other species or inhibit fruit drop may raise the hermaphrodism rate in male Z. americanum (Ainsworth, 2000; Chailakhyan, 1979; Heslop-Harrison, 1956; Marchetti, et al., 1992; Pozo, 2001).

Fruit on male $Z$. americanum plants indicate that those plants are at least partially hermaphroditic. The reproductive mechanisms (outcrossing, selfing, or apomixis) responsible for those fruit are unclear. One clue comes from the high incidence of stenospermocarpy in those fruit, indicating that selfing resulting in inbreeding depression may be responsible for the failed embryos in those stenospermocarpic fruit. An additional clue is the presence of fruit on double-bagged male branches, which should have resulted in no fruit being produced on those branches unless apomixis or selfing were involved. Although not conclusive, these observations support the possibility that male fruit may be due to selfing or apomixis. Further evidence comes from two other observations. In 2013, one of the "fruiting males" had delayed flowering. Flowering began $\approx 2$ weeks after all other $Z$. americanum in the area had finished flowering (the late flowering male was deeply shaded, which may explain the late flowering). Heavy thunderstorms during that 2 -week period should have washed residual pollen from the area, yet the late flowering male bore fruit. If there was no nonself pollen available, then the remaining explanations for seed production or fruit set are selfing or apomixis. Likewise, in 2014 , nine branches in the hermaphroditic group were mistakenly believed to be part of one of the female clones and so pollination bags were placed on those hermaphroditic branches before budbreak. Three of those hermaphroditic bagged branches bore fruit (total of five fruit on those bagged branches). The double bagging used should have excluded all nonself pollen. Branches that were double bagged on the adjacent female clone bore no fruit, indicating that the double bagging method effectively excluded pollen. If fruit on the male $Z$. americanum arise via apomixis, $Z$. americanum has the unusual ability to produce seed asexually on male (primarily staminate) plants - in other words, male apomixis. This phenomenon has also been reported in Cupressus dupreziana where entire embryos were from the pollen (Kagal, 2016).

Exploiting the economic potential of Z. americanum through a breeding program requires actionable knowledge of its reproductive traits. Such a breeding program would be more difficult if the predominate reproductive mechanism in $Z$. americanum was apomixis. The observed high pollen viability rates, the high incidence of male (primarily staminate) plants in the study populations, and the low rates of possible autonomous apomixis suggests that the predominate nonclonal reproductive mechanism in $Z$. americanum is sexual reproduction. Although commonly described as being dioecious, some Z $Z$. americanum plants in the study populations also occasionally produced hermaphroditic flowers. The sporadic, seemingly random occurrence of hermaphroditic flowers on plants with otherwise staminate flowers raises a number of research possibilities, such as determining the cause of hermaphroditic flowers in $Z$. americanum and determining whether hermaphrodism is an inducible trait in $Z$. americanum. Inducible hermaphrodism could be useful in $Z$. americanum breeding because it would allow fruiting traits to be evaluated in male (primarily staminate) plants and would allow male (primarily staminate) plants to be used as the maternal parent where that would be advantageous.

\section{Literature Cited}

Ainsworth, C. 2000. Boys and girls come out to play: The molecular biology of dioecious plants. Ann. Bot. 86:211-221.

Aleza, P., J. Juárez, P. Ollitrault, and L. Navarro. 2010. Polyembryony in non-apomictic citrus genotypes. Ann. Bot. 106:533-545.

Anderson, N.O. and P.D. Ascher. 2000. Fertility changes in inbred families of self-incompatible chrysanthemums (Dendranthema $\times$ grandiflora). J. Amer. Soc. Hort. Sci. 125:619-625.

Asker, S. 1979. Progress in apomixis research. Hereditas 91:231-240.

Augspurger, C.K. 2009. Spring 2007 warmth and frost: Phenology, damage and refoliation in a temperate deciduous forest. Funct. Ecol. 23:1031-1039.

Bafi-Yeboa, N.F.A., J.T. Arnason, J. Baker, and M.L. Smith. 2005. Antifungal constituents of northern prickly ash, Zanthoxylum americanum Mill. Phytomedicine 12:370-377.

Barrett, S.C. 2002. The evolution of plant sexual diversity. Nat. Rev. Genet. 3:274-284.

Bawa, K.S. 1980. Evolution of dioecy in flowering plants. Annu. Rev. Ecol. Syst. 11:15-39.

Bicknell, R.A. and A.M. Koltunow. 2004. Understanding apomixis: Recent advances and remaining conundrums. Plant Cell 16:S228S245.

Bowers, W.S., F. Ortego, X. You, and P.H. Evans. 1993. Insect repellents from the chinese prickly ash Zanthoxylum bungeanum. J. Nat. Prod. 56:935-938.

Cameron, J.W. and M.J. Garber. 1968. Identical-twin hybrids of Citrus $\times$ Poncirus from strictly sexual seed parents. Amer. J. Bot. 55:199-205.

Chailakhyan, M.K. 1979. Genetic and hormonal regulation of growth, flowering, and sex expression in plants. Amer. J. Bot. 66:717-736.

Chen, C., M.T. Lyon, D. O'Malley, C.T. Federici, J. Gmitter, J.W. Grosser, and F.G. Gmitter, Jr. 2008. Origin and frequency of $2 n$ gametes in Citrus sinensis $\times$ Poncirus trifoliata and their reciprocal crosses. Plant Sci. 174:1-8.

Damery, J. 2011. A taste of Sichuan: Zanthoxylum simulans. Arnoldia 68:3.

Darwin, C. 1877. The different forms of flowers on plants of the same species. John Murray, London, UK.

Desai, S. 1962. Polyembryony in Xanthoxylum Mill. Phytomorphology 12:184-189.

Distefano, G., M. Caruso, S. La Malfa, A. Gentile, and E. Tribulato. 2009. Histological and molecular analysis of pollen-pistil interaction in clementine. Plant Cell Rpt. 28:1439-1451.

Distefano, G., A. Hedhly, G. Las Casas, S. La Malfa, M. Herrero, and A. Gentile. 2012. Male-female interaction and temperature variation affect pollen performance in Citrus. Sci. Hort. 140:1-7. 
Erichsen-Brown, C. and E. Brown. 1989. Medicinal and other uses of North American plants: A historical survey with special reference to the eastern Indian tribes. Dover Publ., New York, NY.

Felter, H.W. and J.U. Lloyd. 1898. Xanthoxylum. King's American dispensatory 1898. 18th ed., 3rd rev. 12 Jan. 2014. <http://www. henriettes-herb.com/eclectic/kings/xanthoxylum.html>.

Freeman, D.C., J.L. Doust, A. El-Keblawy, K.J. Miglia, and E.D. McArthur. 1997. Sexual specialization and inbreeding avoidance in the evolution of dioecy. Bot. Rev. 63:65-92.

Gardner, N., R. Felsheim, and A.G. Smith. 2009. Production of maleand female-sterile plants through reproductive tissue ablation. J. Plant Physiol. 166:871-881.

Hartley, T.G. and D.J. Mabberley. 2003. The identity of Picrella Baill. (Rutaceae) with a revision of the genus. Adansonia 25:251-259.

Henderson, M.T., G. Merriam, and J. Wegner. 1985. Patchy environments and species survival: Chipmunks in an agricultural mosaic. Biol. Conserv. 31:95-105.

Heslop-Harrison, J. 1956. Auxin and sexuality in Cannabis sativa. Physiol. Plant. 9:588-597.

Jacobson, M. 1948. Herculin, A pungent insecticidal constituent of southern prickly ash bark. J. Amer. Chem. Soc. 70:4234-4237.

Ju, Y., C.C. Still, J.N. Sacalis, J. Li, and C.T. Ho. 2001. Cytotoxic coumarins and lignans from extracts of the northern prickly ash (Zanthoxylum americanum). Phytother. Res. 15:441-443.

Kagal, U. 2016. Origins: Book 1/12: The origin of death. Paperback Publ., New York, NY.

Katzer, G. n.d. Sichuan pepper and others (Zanthoxylum piperatum, simulans, bungeanum, rhetsa, acanthopodium). 21 Nov. 2012. <http:// www.uni-graz.at/ katzer/engl/Zant_pip.html>.

Kepiro, J.L. and M.L. Roose. 2007. Nucellar embryony, p. 141-149. In: I. Khan (ed.). Citrus genetics, breeding and biotechnology. CAB Intl., Wallingford, UK.

Kho, Y.O. and J. Baer. 1968. Observing pollen tubes by means of fluorescence. Euphytica 17:298-302.

Koltunow, A.M. 1993. Apomixis: Embryo sacs and embryos formed without meiosis or fertilization in ovules. Plant Cell 5:1425-1437.

Koltunow, A.M., K. Soltys, N. Nito, and S. McClure. 1995. Anther, ovule, seed, and nucellar embryo development in Citrus sinensis cv. Valencia. Can. J. Bot. 73:1567-1582.

Maji, T.K. and M.R. Hussain. 2009. Microencapsulation of Zanthoxylum limonella oil (ZLO) in genipin crosslinked chitosan-gelatin complex for mosquito repellent application. J. Appl. Polym. Sci. 111:779-785.

Marchetti, S., C. Zampa, and F. Chiesa. 1992. Sex modification in Actinidia deliciosa var. deliciosa. Euphytica 64:205-213.

Martin, F.W. 1959. Staining and observing pollen tubes in the style by means of fluorescence. Biotech. Histochem. 34:125-128.

Missouri Botanical Gardens. 2014. Zanthoxylum americanum. 29 Oct. 2012. <http://www.missouribotanicalgarden.org/gardens-gardening/ your-garden/plant-finder/plant-details/kc/m900/zanthoxylumamericanum.aspx $>$.
Mosseler, A. and L. Zsuffa. 1989. Sex expression and sex ratios in intraand interspecific hybrid families of Salix L. Silvae Genet. 38:12-17.

Naumova, T.N. 1992. Apomixis in angiosperms: Nucellar and integumentary embryony. CRC Press, Boca Raton, FL.

Nogler, G.A. 1984. Gametophytic apomixis, p. 475-518. In: B.M. Johri (ed.). Embryology of angiosperms. Springer, Berlin, Germany.

Owenby, G.B. and T. Morley. 1991. Vascular plants of Minnesota: A checklist and atlas. Univ. Minnesota Press, Minneapolis, MN.

Pannell, J.R. 2002. The evolution and maintenance of androdioecy. Annu. Rev. Ecol. Syst. 33:397-425.

Patiño, L.O.J., R.J.A. Prieto, and S.L.E. Cuca. 2011. Zanthoxylum genus as potential source of bioactive compounds, p. 185-218. In: I. Rasooli (ed.). Bioactive compounds in phytomedicine. InTech, Rijeka, Croatia.

Popp, J.W. and J.A. Reinartz. 1988. Sexual dimorphism in biomass allocation and clonal growth of Xanthoxylum americanum. Amer. J. Bot. 75:1732-1741.

Porter, D.M. 1976. Zanthoxylum (Rutaceae) in North America north of Mexico. Brittonia 28:443-447.

Pozo, L.V. 2001. Endogenous hormonal status in citrus flowers and fruitlets: Relationship with postbloom fruit drop. Sci. Hort. 91:251-260.

Reinartz, J.A. and J.W. Popp. 1987. Structure of clones of northern prickly ash (Xanthoxylum americanum). Amer. J. Bot. 74:415-428.

Ross, M.D. 1980. The evolution and decay of overdominance during the evolution of gynodioecy, subdioecy, and dioecy. Amer. Nat. 114:607-620.

Ross, M.D. 1982. Five evolutionary pathways to subdioecy. Amer. Nat. 119:297-318.

Savidan, Y. 1999. Apomixis: Genetics and breeding. Plant Breed. Rev. 18:13-86.

Towil, L.E. 2010. Long-term pollen storage. Plant Breed. Rev. 13:179-207.

U.S. Department of Agriculture. 2012a. PLANTS database profile for Zanthoxylum americanum Mill. 29 Oct. 2012. <http://plants.usda.gov>.

U.S. Department of Agriculture. 2012b. Miscellaneous and processed products import manual. 20 Nov. 2017. <http://www.aphis.usda.gov/ import_export/plants/manuals/ports/downloads/miscellaneous.pdf $>$. van Doorn, W.G. and A.D. Stead. 1997. Abscission of flowers and floral parts. J. Expt. Bot. 48:821-837.

Watanabe, S., N. Noma, and N. Takayoshi. 2016. Flowering phenology and mating success of the heterodichogamous tree Machilus thunbergii Sieb. et Zucc (Lauraceae). Plant Species Biol. 31:29-37.

Webb, C.J. 1979. Breeding systems and the evolution of dioecy in New Zealand apioid Umbelliferae. Evolution 33:662-672.

West, D.A. and W.N. Hazel. 1996. Natural pupation sites of three North American swallowtail butterflies: Eurytides marcellus (Cramer), Papilio cresphontes Cramer, and P. troilus L. (Papilionidae). J. Lepid. Soc. 50:297-302.

Yinghong, L., W. Fuxiong, and Q. Nanfen. 1987. Apomixis in Zanthoxylum bungeanum and Z. simulans. Acta Genet. Sinica 2:003. 